\title{
The Intuition behind the Non-Identity Problem
}

\author{
MATEJ SUŠNIK \\ Institute of Philosophy, Zagreb, Croatia
}

\begin{abstract}
This paper examines a well-known non-identity case of a mother who chooses to conceive a blind child instead of a sighted one. While some people accept the non-identity argument and claim that we should reject the intuition that the mother's act is morally wrong, others hold onto that intuition and try to find a fault in the non-identity argument. This paper proposes a somewhat middle approach. It is argued that the conclusion of the non-identity argument is not necessarily in conflict with our intuitive response to this case.
\end{abstract}

Keywords: Blameworthiness; choice; non-identity argument; nonidentity problem; permissibility.

\section{Introduction}

In non-identity cases, one's present actions determine the life's quality of people who do not yet exist. David Boonin (2014: 2), modifying the example proposed by Derek Parfit (1982: 118), thinks of a woman named Wilma who, due to her present health condition, faces a choice between conceiving a blind child now or conceiving a sighted child a couple of months later. Wilma finds it inconvenient to wait with conception until her condition is cured, so she decides to conceive now. Nine months later, she gives birth to a blind girl named Pebbles. This kind of case generates the non-identity problem (NIP): although most people have the intuition that it was wrong of Wilma to conceive Pebbles, it is difficult to explain what makes her act morally wrong. ${ }^{1}$

${ }^{1}$ Boonin's book presents the most extensive and detailed discussion of the nonidentity problem in contemporary literature. Even though I focus on Boonin's central 
That this intuition may not be firmly grounded is established by the non-identity argument (NIA). ${ }^{2}$ While Pebbles's disability negatively affects her life's quality, it does not affect it to the extent that it makes her life not worth living. Also, had Wilma conceived later, she would have given birth to a different child. It follows that Pebbles could have either existed as blind or not existed at all. Therefore, Wilma's act of conceiving Pebbles did not make Pebbles worse off than she would have been, and hence it was not morally wrong of Wilma to bring her into existence. ${ }^{3}$

As Boonin remarks, the NIP arises only for those who find implausible the NIA's conclusion that "Wilma's act of conceiving Pebbles is not morally wrong" (2008: 130; 2014: 27). ${ }^{4}$ As he points out, they can solve the NIP either by abandoning the intuition that gives rise to it or by rejecting some of the NIA premises.

While I share the doubt regarding that intuition's reliability, my reasons for such a doubt differ in one crucial respect. The reason why the intuition about the Wilma case should be rejected does not lie in the force of the NIA, but in the fact that it is mistakenly described as the belief that Wilma's act of conceiving Pebbles is morally wrong.

\section{Opposing intuitions}

\section{Consider the following case:}

Incompetent physician: Susan wants to conceive a child and thus makes an appointment with a physician. Since the physician is incompetent, he does not inform Susan that her child will be born blind if she conceives now. He also does not inform her that this can be prevented if Susan postpones conception for a couple of

example of Wilma, the argument developed in this paper applies equally to the other cases of this sort, such as Gregory Kavka's "case of a slave child” (Kavka 1982: 100). It does not apply to other non-identity cases, such as those that involve a choice between two different social policies (for example, see Parfit 1984: 361-62).

${ }^{2}$ Boonin carefully distinguishes between the "non-identity problem" and the "non-identity argument". The non-identity argument, he notes, "gives rise to the non-identity problem" (Boonin 2014: 3).

${ }^{3}$ Boonin formulates the NIA in the following way:

"P1: Wilma's act of conceiving now rather than taking a pill once a day for two months before conceiving does not make Pebbles worse off than she would otherwise have been

P2: If A's act harms B, then A's act makes B worse off than B would otherwise have been

P3: Wilma's act of conceiving now rather than taking a pill once a day for two months before conceiving does not harm anyone other than Pebbles

P4: If an act does not harm anyone, then the act does not wrong anyone

P5: If an act does not wrong anyone, then the act is not morally wrong

C: Wilma's act of conceiving Pebbles is not morally wrong" (Boonin 2014: 27).

${ }^{4}$ For example, Wilma's act will probably not seem morally impermissible to those who believe that blindness and similar impairments are not bad. Moreover, some of those people may even think that such impairments are good. For example, see Cooper (2007). 
months until she cures her health condition by taking a certain medication. Not being aware of all this, Susan conceives now and nine months later gives birth to a blind girl named Kelly.

I presume that most people, confronted with this case, will not have the intuition that Susan did something morally wrong. However, this is puzzling. If our intuition in the case of Wilma is that her act of conceiving Pebbles was morally wrong, how is it that we do not have the same intuition in the case of Susan? Is the act of conceiving a blind child not the same in both cases?

Perhaps not. It could be replied that Wilma and Susan performed different act-types. More specifically, one could point out that our intuition in the case of Wilma is not that her act of conceiving a blind child rather than a sighted one has the property of being wrong, but that her act of deliberately and knowingly conceiving a blind child rather than a sighted one has the property of being wrong. Thus, it all depends on how the act-type in question is described. ${ }^{5}$ Since the latter act-type is instantiated only by Wilma, the answer might go, there is nothing strange about our having different intuitions regarding the two cases.

However, here is where the trouble starts. This answer suggests that to account for the different moral reactions to the two cases, one must focus on the agent and the circumstances under which the act was performed. While Wilma's act was performed deliberately and in full knowledge of the outcome, Susan lacked the relevant information about her options.

But why would one feel that these features make Wilma's act of conceiving Pebbles morally wrong? To think so is to assume that what appear to be the properties of an agent (e.g., Wilma knowingly and deliberately conceiving Pebbles) can sometimes affect the rightness or wrongness of the performed act. Although something like this assumption has been endorsed by a number of authors-most notably in the context of the discussion about the relevance of intentions to moral permissibility -it has also been forcefully criticized (e.g., Thomson 1991; Scanlon 2008). And some of that criticism is that while the intentions with which an agent acts sometimes alter the nature of the act, they do not alter the moral nature of the act. For example, someone who deliberately and out of malice kills another person commits the act of murder. And the act of murder is distinguished from the act of manslaughter, which does not require the presence of a bad intention. Therefore, murder and manslaughter are different acts, but they are still both wrong (see, for example, Scanlon 2008: 12-13).

In that regard, it remains unclear why the fact that Wilma knowingly and deliberately conceived a blind child should make us react differently to the two cases. Perhaps we might think that Wilma's act of conceiving Pebbles is worse than Susan's act of conceiving Kelly, but

${ }^{5}$ For a discussion of the different ways in which act-types can be described, see Wedgwood (2011) and FitzPatrick (2012). 
to say of two acts that one is worse than the other is not to say that one is wrong while the other is not.

In response to this, one could say that the accurate description of an act-type instantiated by Wilma should also include the reasons behind her choice. Then it would become apparent that it is the objectionable reason behind Wilma's choice that makes us respond differently to the two cases. Thus, while Susan instantiated an act-type conceiving a blind child rather than a sighted one, Wilma instantiated an acttype deliberately and knowingly conceiving a blind child rather than a sighted one for the reasons of convenience.

But this suggestion does not seem to avoid the problem mentioned above: it assumes that the reason for which Wilma performed her act has the power to affect its rightness or wrongness. However, it is difficult to explain how the reason behind Wilma's choice could possess such power. If it is plausible to say that the moral permissibility of an act is determined by its effects on others, endorsing the above suggestion would mean that one should explain how the reason for which Wilma conceived Pebbles negatively affected Pebbles. Furthermore, the NIA also stands in the way of accomplishing this task since it seems to establish that Pebbles is neither wronged nor harmed by Wilma's act.

The NIA applies to Susan's case just as it applies to Wilma's case. ${ }^{6}$ It establishes that neither of them did anything morally wrong. However, the NIP arises only in Wilma's case. This is because our intuition about Susan's case is compatible with the conclusion of the NIA: her act does not seem morally wrong. But Wilma's act, on the other hand, seems morally wrong. This difference in our intuitive responses requires explanation.

In the remainder of this paper, I suggest that the problem disappears once we realize that our moral reaction to the Wilma case has nothing to do with the alleged wrongness of her act at all.

\section{Two assessments of Wilma's act}

When introduced to the Wilma case, most people will say that there is something morally objectionable about her act. But the term 'morally objectionable' seems to be ambiguous between 'morally wrong' and 'morally bad'. To take the former interpretation is to direct the discussion to the morally relevant features that make an action right or wrong. In particular, it is to focus on the (possible) harmful effects Wilma's act of conceiving Pebbles has (will have) on Pebbles.

But that is not the case if the term 'morally objectionable' is taken to mean 'morally bad'. Here one does not assess Wilma's act of conceiving Pebbles, but rather her acting on a choice to conceive Pebbles. Of course, her choice manifests itself in the act of conceiving Pebbles, but that does not mean that it cannot be assessed independently of that

${ }^{6}$ This can be easily seen if one replaces "Wilma" with "Susan" and "Pebbles" with "Kelly" in the NIA as it is formulated by Boonin. 
act. Her acting on that choice reveals her judgment that conceiving a blind child was the best course of action in the given circumstances. ${ }^{7}$

With that in mind, we can focus all our attention on the reasons on which her judgment was based and assess her decision-making process. Such an assessment would essentially be backward-looking and as such should be distinguished from a forward-looking assessment that primarily focuses on the results of her choice. This latter assessment is, we might say, concerned with permissibility. And assuming that the NIA is sound, we should say that Wilma's act does not negatively affect Pebbles and is thus morally permissible. The former assessment, on the other hand, is not concerned with permissibility but rather with Wilma's subjective point of view and her deliberative process that resulted in her choosing to conceive a blind child. In that regard, one might say, the attribution of blame would be appropriate if her reasons for choosing to conceive a blind child turned out to be morally unacceptable. Thomas Scanlon describes the distinction between these two kinds of assessments in the following way:

[I] $t$ is the distinction between the permissibility of an action and a special kind of agent assessment, in which what is being assessed is not the agent's overall character but rather the quality of the particular piece of decision making that led to the action in question. (Scanlon 2008: 27-8)

Now, most people firmly hold onto their intuition that there is something morally objectionable about Wilma's act even after they learn about the NIA. Of course, it is quite possible that they are mistaken and that the explanation for this, as Boonin remarks, lies in our moral intuitions not being "sufficiently fine tuned to respond at every instance to what, at a purely intellectual level, we understand to be the case" (Boonin 2008: 148). But there is a simpler explanation available, and that is that our intuition in the Wilma case is not about the alleged wrongness of her act all.

In support of this suggestion, it should be noted that no argument has been provided in favor of the claim that our initial moral response to this case should be described as the belief that Wilma's act of conceiving Pebbles is morally wrong. Quite the contrary, this is merely assumed. And indeed, there are at least two reasons to think that this response should be described differently, namely as the belief that Wilma acted badly. ${ }^{8}$ First, we would then be able to explain why we hold different intuitions about the cases of Wilma and Susan (Susan does not act badly). Second, we would also be able to explain why we cannot easily reject our intuition about the Wilma case despite the force of the NIA (the NIA is concerned with the permissibility of Wilma's act). ${ }^{9}$

${ }^{7}$ The relation between judgment and choice is discussed by Holton (2009).

${ }^{8}$ I borrow the phrase "acts badly" from FitzPatrick (2012). FitzPatrick develops a similar view as the one defended in this paper, but in an entirely different context.

${ }_{9}$ Perhaps it might be objected that interpreting our intuition in this way implausibly implies that one can be blameworthy even if one has not done anything wrong. But not everyone finds this implication controversial (see, e.g., Capes 2012; Scanlon 2008). 


\section{Why Wilma acts badly}

But why think that Wilma acts badly when she chooses to conceive Pebbles? To answer this question, we should focus on her deliberative process and look deeper into the reasons behind her choice. And, as some authors have already pointed out (Wasserman 2019: 65-7), once we focus on the fact that her choice is exclusively determined by her convenience, there is room to argue that her act manifests insensitivity to the harmful condition of her future child.

Before Wilma has acted on her choice to conceive Pebbles, as David Wassermen notes, all she knew about her future child was that the time of his/her conception would determine whether he/she would be born blind or sighted. This point is crucial. For, as Wasserman convincingly argues, it enables us to see that, insofar as we consider things from Wilma's perspective, her choice came down to choosing, not between two different children, but between the condition of blindness and the condition of sightedness. And the moment Wilma acts on her choice to conceive Pebbles, her act signals her indifference and insensitivity to the vast difference between these two conditions (Wasserman 2019: 75-81).

However, Wasserman does not seem to realize that Wilma's insensitivity does not make her act wrong, but rather that it makes her act badly. And this allows Boonin to quickly dismiss the insensitivity charge as unfounded. In his recent paper on the NIP, Boonin offers three possible responses to the claim that Wilma's act manifests insensitivity to the condition of blindness (Boonin 2019: 146-147). But if we keep in mind that our intuitive reaction to the Wilma case is not about her act's wrongness, it becomes easier to see that none of them are successful.

Boonin first considers a case in which you are faced with a choice between saving a blind or saving a sighted child from drowning. Since the sighted child is further away, you find it more convenient to save the blind child. Now, it seems that most people would agree, Boonin says, that saving the blind child out of convenience in this case does not make you insensitive to the harm of blindness. And if so, why is the case of Wilma any different? (Boonin 2019: 146-147)

However, there is a crucial difference between the two cases. Namely, we do not believe that the badness of blindness is a reason not to choose to save the blind child from drowning, but we do believe that the badness of blindness is a good reason not to choose to bring a blind child into existence. This point has been first made by David Benatar, who points out that we do not apply the same standards when determining whether a "life is worth continuing" and whether a "life is worth creating" (Benatar 2006: 23). Thus, while acting out of convenience in the drowning case is not a sign of insensitivity, the same cannot be said about Wilma. Her finding it more convenient to conceive a blind child makes her insensitive to the forceful reason that speaks against such a choice. 
There is a second way to rule out the insensitivity objection. Even if one grants that Wilma's act reveals insensitivity, Boonin remarks, "this would not show that her act was wrong, only that her motive was objectionable" (Boonin 2019: 146).

However, as it should already be clear, this does not present a problem for the view endorsed here. One could argue that Wilma acts badly and thus manifests insensitivity even if she has not done anything wrong. The key point here is that the judgment about Wilma's insensitivity is entirely independent of Pebbles coming into existence. Wilma's act, I suggest, would manifest an equal degree of insensitivity even if, by some coincidence, it did not result in the creation of a blind child. Although her acting on a choice to conceive Pebbles led to her actually conceiving Pebbles, our intuitive moral reaction is a reaction to the former, not the latter. And her merely acting on that choice makes it sufficient for us to say that her act manifests an inappropriate parental attitude to her future child's bad condition.

Boonin's third response to the insensitivity charge involves slightly changing the original example. He now asks us to imagine that Wilma is familiar with the NIA and finds it convincing. Since she now has a good reason to believe that Pebbles will neither be harmed nor wronged by being brought into existence, it cannot be correct to say that her acting on a choice to conceive Pebbles displays insensitivity (Boonin 2019: 146).

While this may seem like a promising route to take, I believe that the initial difficulty remains. The problem with this response is that it fails to allow for the possibility that Wilma's acting badly may be compatible with her act being morally permissible. The fact that Wilma is now aware of the considerations that justify her act only shows that she can defend it against the impermissibility charge. But it does not show that she is not insensitive if she performs it. As Joshua Gert notes in a somewhat different context, "[i]n many cases justifying considerations are ones that it would be morally better to ignore" (Gert 2004: 35).

Wilma's act, even if permissible, is in tension with our understanding of the nature of the relationship between parents and children. Following the lead of Scanlon, we might hold that such a relationship is, just like any other, "constituted by certain attitudes and dispositions" (Scanlon 2008: 131). And these attitudes and dispositions, Scanlon correctly points out, can be deemed more or less appropriate, depending on how far they are from the ideal standard. If it is plausible to say that prospective parents are, just like actual parents, expected to care for the welfare of their (future) children, then there is a reason to think that Wilma's act is not in line with such expectations. It is not enough to stipulate that Wilma believes that the NIA justifies her act in order to rule out the charge that she does not sufficiently care about the condition her future child will be born with. 


\section{Conclusion}

Various solutions to the NIP have been proposed. Some people (David Boonin being the most prominent example) argue that the NIA forces us to abandon the intuition that Wilma's act is morally wrong. And those who, on the other hand, believe that Wilma's act is morally wrong try to find a fault in the NIA. I have proposed a somewhat middle approach to the NIP. What gives rise to the NIP (at least in cases like that of Wilma) is not the NIA but rather the way our intuitive moral response is described. After being introduced to the Wilma case, we do not form the belief that her act is morally wrong. Instead, we form the belief that Wilma acts badly. I conclude that even if the NIA is sound, it leaves our intuitive reaction to the Wilma case unscathed. ${ }^{10}$

\section{References}

Boonin, D. 2014. The Non-Identity Problem and the Ethics of Future of People. New York: Oxford University Press.

Boonin, D. 2019. "Solving the Non-Identity Problem: A Reply to Gardner, Kumar, Malek, Mulgan, Roberts and Wasserman." Law, Ethics and Philosophy 7: 127-156.

Benatar, D. 2006. Better Never to Have Been. The Harm of Coming into Existence. New York: Oxford University Press.

Capes, J. A. 2012. "Blameworthiness Without Wrongdoing." Pacific Philosophical Quarterly 93 (3): 417-437.

Cooper, R. 2007. "Can It Be a Good Thing to Be Deaf?" Journal of Medicine and Philosophy 32 (6): 563-583.

FitzPatrick, W. J. 2012. "Intention, Permissibility, and Double Effect." In M. Timmons (ed.) Oxford Studies in Normative Ethics Vol. 2. Oxford: Oxford University Press: 97-127.

Gert, J. 2004. Brute Rationality: Normativity and Human Action. Cambridge: Cambridge University Press.

Holton, R. 2009. Willing, Wanting, Waiting. Oxford: Oxford University Press.

Kavka, G. 1982. "The Paradox of Future Individuals." Philosophy and Public Affairs 11 (2): 93-112.

Parfit, D. 1982. "Future Generations: Further Problems." Philosophy and Public Affairs 11 (2): 113-172.

Parfit, D. 1984. Reasons and Persons. Oxford: Oxford University Press.

Scanlon, T. M. 2008. Moral Dimensions: Permissibility, Meaning, Blame. Cambridge: Harvard University Press.

Thomson, J. J. 1991. "Self-Defense." Philosophy and Public Affairs 20 (4): 283-310.

Wasserman, D. 2019. "Chasing the Elusive Wrongdoing Intuition." Law, Ethics and Philosophy 7: 63-83.

Wedgwood, R. 2011. "Defending Double Effect.” Ratio 4: 384-401.

${ }^{10}$ I thank the two anonymous reviewers for their helpful remarks. My thanks also go to Neven Sesardic who commented on an earlier version of the paper. This article is an output of the project "Harm, Intentions and Responsibility" supported by Croatian Science Foundation (Grant No. UIP-2017-05-4308). 